\title{
The relationship between post-operative time and cardiac autonomic modulation in breast cancer survivors
}

\author{
Mariana Romanholi Palma ${ }^{\mathrm{a}, *}$, Luiz Carlos Marques Vanderlei ${ }^{\mathrm{b}}$, Fernanda Elisa Ribeiro ${ }^{\mathrm{a}}$, \\ Alessandra Madia Mantovani ${ }^{\mathrm{c}}$, Diego Giulliano Destro Christofaro ${ }^{\mathrm{b}}$, Cristina Elena Prado Teles Fregonesi ${ }^{\mathrm{b}}$ \\ ${ }^{\text {a }}$ Faculty of Science and Technology FCT/UNESP, Presidente Prudente, SP, Brazil \\ ${ }^{\mathrm{b}}$ Department of Physical Therapy and Graduate Program in Physical Therapy, Faculty of Science and Technology FCT/UNESP, Presidente Prudente, SP, Brazil \\ ${ }^{c}$ Biosciences Institute UNESP, Rio Claro, SP, Brazil
}

\section{A R T I C L E I N F O}

\section{Article history:}

Received 1 August 2016

Received in revised form 29 August 2016

Accepted 15 September 2016

Available online 17 September 2016

\section{Keywords:}

Autonomic nervous system

Breast neoplasms

Heart rate variability

\begin{abstract}
A B S T R A C T
Background/objectives: Breast cancer survivors present autonomic dysfunction when evaluated by their heart rate variability (HRV). The purpose of this study is to investigate the relationship between post-operative time and cardiac autonomic modulation in breast cancer survivors and compare these values to those of women without cancer. Methods: This is a cross-sectional study consisting of 45 women from 35 to 70 years old. These women were divided into two after breast cancer groups (BCG1 and BCG2) and a control group (CG). Group BCG1 consisted of women who had undergone breast cancer surgery within the last 18 months and BCG2 those whose postoperative periods were more than 18 months. The control group was formed by cancer-free women. HRV indices were used in the time and the frequency domain and geometric indexes. Results: The indices in millisecond, RMSSD (BCG1 = 19.83; BCG2 = 14.99; CG = 31.46), SD1 (BCG1 = 14.03; BCG2 = 10.61; $\mathrm{CG}=22.27)$, SD2 (BCG1 = 39.17; BCG2 = 35.28; CG = 61.16), $\mathrm{SDNN}(\mathrm{BCG} 1=29.58$; $\mathrm{BCG}=26.12$; $\mathrm{CG}=$ 46.36) and HF in milliseconds squared (BCG1 = 194.2; BCG2 = 91.07; $C G=449.4$ ) showed statistically significant reductions in the breast cancer groups compared to the CG $(\mathrm{p} \leq 0.0001)$. Lower SD1 index values were observed when comparing BCG2 to BCG1. Conclusions: Breast cancer survivors regardless of their postoperative period exhibited a decrease in overall variability and both sympathetic and parasympathetic activity when compared to women without the disease. The group with the longer postoperative period manifested more pronounced autonomic modulation changes.
\end{abstract}

(c) 2016 Elsevier Ireland Ltd. All rights reserved.

\section{Introduction}

Breast cancer is the second most common cancer in the world and the most common type among women [1]. In 2012, 1.67 million cases of breast cancer were diagnosed throughout the world, and another estimated 6.23 million new cases will be diagnosed by 2017 [1].

Anti-cancer treatments are aggressive and can lead to various impairments, including cardiovascular diseases [2], such as hypertension, heart failure, thrombosis and acute coronary syndromes [3]. Moreover, changes are observed in the functioning of the autonomic nervous system (ANS) [4,5] which is responsible for cardiac modulation among other things [6].

One way to clinically assess autonomic regulation is to analyze the heart rate variability (HRV), which reflects periodic and non-periodic changes in heart rate (HR) [7,8]. This is a noninvasive and reliable way

\footnotetext{
* Corresponding author.

E-mail address: marianaromanholi@hotmail.com (M.R. Palma).
}

to come to inferences about the sync [7]. HRV enables us to evaluate health and identify psychological and physiological changes [6,9].

Studies which analyze the HRV of patients with a variety of cancers consistently show reduced vagal tone $[10,11]$. Specifically in women with breast cancer, studies indicate changes in HRV immediately after surgery [4] and 6 months to 1 year after treatment is completed [2]. However, a search through relevant literature revealed that there are no studies evaluating the possible changes in long-term cardiac autonomic modulation. Studies which examine breast cancer survivors' HRV rates during different postoperative periods and compare them to individuals without cancer are nonexistent.

Considering that cancer is a major public health problem [12], as well as knowing that the disease and its treatments are aggressive [2] and can reflect negatively on HRV [2,4], we need to know the possible autonomic changes in women who have undergone breast cancer treatment. These women's HRV indices need to be taken at different times following their surgeries and compared with the indices of cancer-free women. This would enable clinicians and researchers to develop 
treatments which improve autonomic modulation and reduce cardiovascular risks in the population of cancer survivors.

Within this context, we are seeking in this study to investigate the relationship between postoperative time and cardiac autonomic modulation in breast cancer survivors and then compare these figures to those of women without cancer. We hypothesize that after breast cancer surgery women could present greater changes in cardiac autonomic modulation and that these changes could be influenced by postoperative time.

\section{Methods}

2.1. Type of study and ethical aspects

This is a cross-sectional study developed in the Physiotherapy Clinical Studies Laboratory (LECFisio) of the College of Science and Technology (FCT) - São Paulo State University (UNESP), the Campus of Presidente Prudente, São Paulo, Brazil. This study was done in accordance with the rules of the National Commission of Ethics in Research and was approved by the Research Ethics Committee of the FCT/UNESP (Protocol No. 046982/ 2014). All volunteers in this study signed an Informed Consent Form when they agreed to participate.

\subsection{Subjects and selection criteria}

Women between 35 and 70 years old were invited to participate in this study. These women were divided into three groups: two after breast cancer groups (BCG1 and BCG2) and a control group (CG). The after breast cancer groups were composed of women who had undergone breast cancer surgery, quadrantectomy or mastectomy, anywhere from with 2 months to 10 years earlier. These women came from a local breast cancer support group or were referred directly to us by local breast cancer specialists. Groups 1 and 2 were delimited by the average post operative period, which was 18 months. Women who were below the average made up BCG1 and those above the average composed BCG2. Women of approximately the same age but without breast cancer made up the CG. These women were invited from the community.

To qualify for this study, the participants could not present respiratory diseases, arrhythmias, pacemakers or heart transplants [6], nor could they be smokers and/or drinkers. Women participating after breast cancer surgery were required to have their physician's consent, as well as be free of any known metastases and not be undergoing chemotherapy or radiation treatment. Volunteers who presented RR interval series with an error greater than $5 \%$ were excluded from the study.

The calculation of sample size was based on the study of Caro-Morán et al. [2] and was determined using the RMSSD index. Taking into account a standard deviation for group A (control) of $22.17 \mathrm{~ms}$ and for the B group (breast cancer) $23.52 \mathrm{~ms}$, the $80 \%$ test power, alpha error of $5 \%$ for a two-tailed test, and the difference of 29.83 between the medium and a sample loss of $20 \%$ (related to possible HRV reading errors), the minimum sample size was determined to be 12 subjects for each group.
Fig. 1 uses a diagram to show how the participants of the breast cancer groups, BCG1 and BCG 2 which is a total 30 volunteers with 15 in each group, were selected. The CG was also composed of 15 participants.

\subsection{Delineation of the study}

Data was collected at a room temperature of between 21 and $24^{\circ} \mathrm{C}[13]$, and always in the morning to avoid circadian variations. The movement of people inside the room was restricted during the evaluation. The participants were required to not ingest alcoholic beverages and/or stimulants, such as coffee and tea, for a minimum of $12 \mathrm{~h}$ prior to their evaluation, in order to prevent these substances from directly influencing their cardiac autonomic behavior during collection [13]. Participants were informed about the data collection procedure and asked to not talk, use the cell phone or sleep during the procedure.

The evaluation protocol included: a) initial assessment, b) anthropometric evaluation, c) measurement of HR and blood pressure (BP), and d) evaluation of autonomic modulation of HR.

\subsection{Initial assessment}

Personal data (age, ethnicity, marital status and education) as well as information about their menstrual cycle and the presence of comorbidities were collected during the assessment. Women who had been without menstrual cycles for longer than one year were considered to be in menopause and the women who had been without menstrual cycles for less than one year were considered climacteric [14]. Women with no menstrual flow due to cancer treatments were not classified as either menopause or climacteric. The participants of BCG1 and BCG2 were questioned about their breast cancer surgery, the type of surgery and adjuvant treatments (chemotherapy, radiotherapy and hormone therapy).

\subsection{Anthropometric evaluation}

We collected the weight and height of the participants and used them to calculate their body mass index (BMI), using the formula weight (kilograms) divided by height (meters) squared [15]. The values of weight and height were taken with a digital scale and stadiometer (Welmy ${ }^{\circledR}, \mathrm{W} 110 \mathrm{H}$, Brazil). As they were weighed and measured, the participants stood with their arms extended along their bodies, wearing light clothing and no shoes.

\subsection{HR and BP measurement}

The HR was measured by a Polar S810i (Polar, Finland) and BP was taken by a stethoscope (Littmann, Saint Paul, USA) and aneroid sphygmomanometer (Tycos®, CE0050, USA), in accordance with the criteria outlined by the VI Brazilian Guidelines for Hypertension [16]. These parameters were taken only once with each individual sitting at rest. To avoid errors in BP readings, a single evaluator performed all BP measurements.

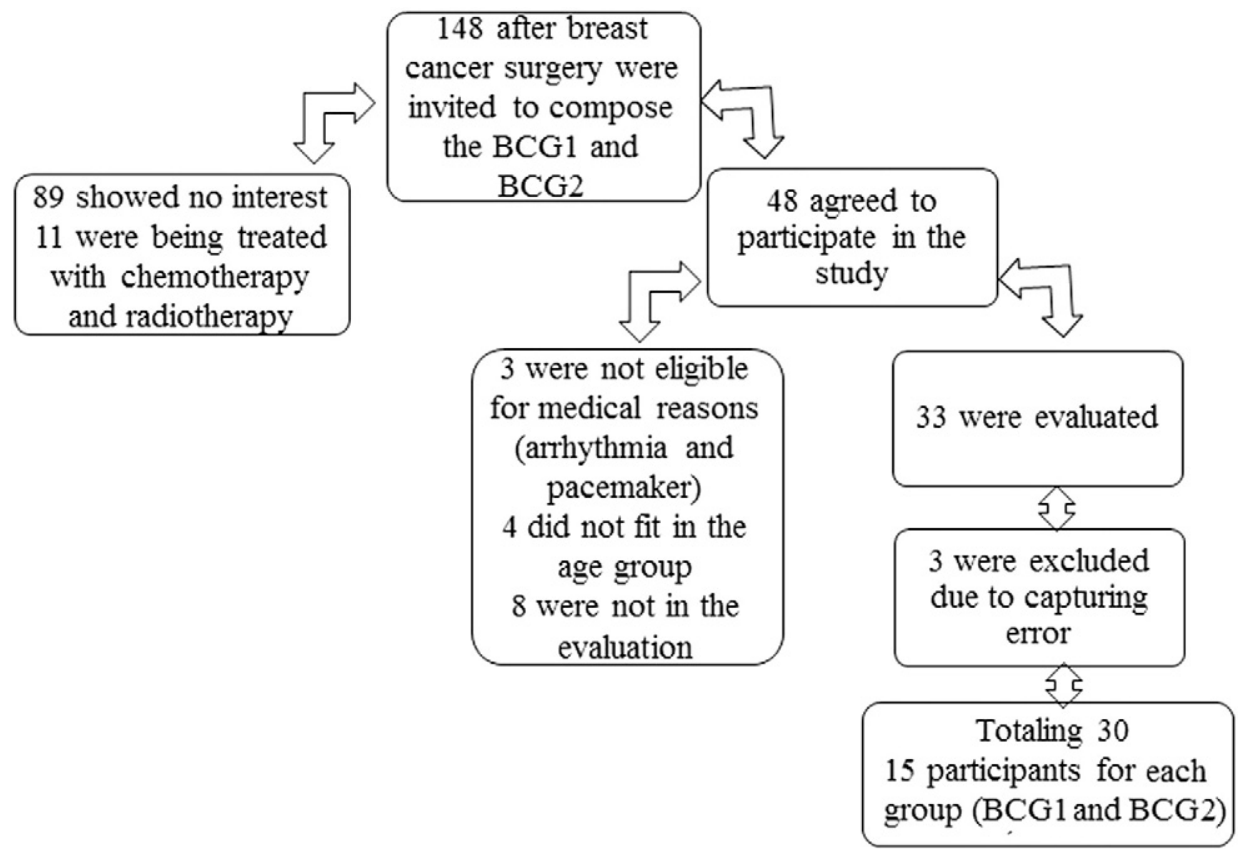

Fig. 1. Diagram representing the selection process for volunteers composing the post breast cancer groups (BCG1 and BCG2). 


\subsection{Evaluation of the autonomic modulation of the $H R$}

Autonomic modulation assessment was performed by analyzing HRV using the Polar S810i (Polar, Finland), a piece of equipment that is validated to capture beat-to-beat HR and use in the calculation of HRV indices $[17,18]$. For this assessment, a chest band containing two electrodes mounted on a sealed electronic transmitter was placed on the distal third of the participant's sternum. This chest band captured the electrical impulses of the heart and transmitted the information through an electromagnetic field to a HR receiver on the participant's wrist.

For the HRV analyses, the participant's HR was recorded beat-to-beat for 30 min while they lay on a bed breathing spontaneously. Using the series of RR intervals that were obtained, a digital filter was made which, supplemented by a manual filter, eliminated premature ectopic beats and artifacts. Only series with more than $95 \%$ sinus rhythm were included in the study [19]. The HRV analysis was performed using linear methods (time and frequency domains) and nonlinear (Poincaré plot), using 1000 RR intervals taken from the more stable trace periods. The software used for the analysis of this data was the Kubios HRV analysis version 2.2 (Kuopio, Finland) [20].

\subsection{HRV analysis}

The RMSSD and SDNN were used for HRV analysis in the time domain. The RMSSD index represents parasympathetic activity and is defined as the square root of the square average of the differences between adjacent normal RR intervals for a period of time expressed in milliseconds (ms) $[6,21]$. The SDNN reflects the involvement of both the SNA branches and represents the average standard deviation of all normal RR intervals expressed in ms [6].

For HRV analysis in the frequency domain, we used the spectral components of low frequency ( $\mathrm{LF}-0.04$ to $0.15 \mathrm{~Hz}$ ) and high frequency ( $\mathrm{HF}-0.15$ to $0.4 \mathrm{~Hz}$ ) in normalized units and in milliseconds squared $\left(\mathrm{ms}^{2}\right)$ and the ratio between these components ( $\mathrm{LF} / \mathrm{HF}$ ) [6]. The LF corresponds to sympathetic and parasympathetic activity with sympathetic predominance. HF indicates vagal tone and the LF/HF ratio represents the sympatheticvagal balance on the heart. Spectral analysis was calculated using the Fast Fourier Transform (FFT) algorithm [6].

We performed the analysis of the Poincaré plot both quantitatively and qualitatively. The indices SD1, SD2 and SD1/SD2 ratio were calculated quantitatively. SD1 is an index of instantaneous recordings of beat-to-beat variability and represents parasympathetic activity, while the SD2 index records the long-term HRV and reflects the overall variability. The ratio of both (SD1/SD2) shows the ratio between short and long variations of RR intervals $[6,22]$.

The plot was analyzed qualitatively by means of the patterns formed by its attractor, following the model described by Tulppo et al. [23]. A normal plot is characterized by a pattern in which an increase in the dispersion of RR intervals beat-to-beat can be observed at the same time as RR intervals increase. A plot with less variability produces a pattern with a small overall beat-to-beat dispersion and no increase in RR intervals over the long term.

\subsection{Statistical analysis}

The descriptive statistical method was used to define this population's characteristics and the values were expressed as mean, standard deviations and percentages. The Chisquare test was applied to compare the percentage values. A qualitative analysis of the Poincaré plot was performed using a scatter chart made in Excel.

Details of the HRV indices were presented as mean, standard deviations and confidence intervals. In order to compare the groups to each other, we applied analysis of covariance (ANCOVA) which was adjusted for age and BMI of the volunteers. Possible differences between the groups' averages in relation to HRV indices were tested using Tukey's post hoc test. The size of the effect's differences was verified by effect size through Eta squared [24]. The statistical program used was SPSS Statistics 17.0 and the significance setting was $\mathrm{p}<0.05$.

The HRV indices were tested for normality using the Shapiro-Wilk test. The Student's $t$ test was applied to paired data (RRtri, TINN and SD1/SD2) and the Wilcoxon test was applied to unpaired data (SD1 and SD2). The statistical program used was SPSS Statistics 17.0 and the level of significance was set at $\mathrm{p}<0.05$.

\section{Results}

Table 1 shows data which characterizes the groups.

The clinical characteristics of the breast cancer groups are presented in Table 2. It is noteworthy that only $20 \%$ of BCG1 and $13.3 \%$ of BCG2 did adjuvant treatment with chemotherapy and/or radiotherapy.

The HRV indices in the time and frequency domains are shown in Table 3 and derivatives of the Poincaré plot in Table 4.

The RMSSD indexes, HFms ${ }^{2}$, SD1, SD2 and SDNN show a statistically significant reduction $(\mathrm{p} \leq 0.0001)$ in the breast cancer groups when compared to the cancer-free group. Lower values in the SD1 index were observed in BCG2 as compared to BCG1. LFms ${ }^{2}$ values were also reduced in the cancer group, but this is only statistically significant

\section{Table 1}

Characterization of women from breast cancer groups (BCG1 and BCG2) and control group (CG). Data presented as mean \pm standard deviation or percentile, followed by p-value. $n=45$.

\begin{tabular}{|c|c|c|c|c|}
\hline & $\begin{array}{l}\text { BCG1 } \\
(n=15)\end{array}$ & $\begin{array}{l}\text { BCG2 } \\
(n=15)\end{array}$ & $\begin{array}{l}\text { CG } \\
(n=15)\end{array}$ & p-Value \\
\hline Age (years) (mean \pm SD) & $51.1 \pm 8.6$ & $56.3 \pm 7.4$ & $51.2 \pm 10.8$ & 0.215 \\
\hline BMI $\left(\mathrm{kg} / \mathrm{m}^{2}\right)($ mean $\pm \mathrm{SD})$ & $27.2 \pm 7.3$ & $26.5 \pm 3.9$ & $25.5 \pm 3.5$ & 0.655 \\
\hline \multicolumn{5}{|l|}{ Ethnicity (\%) } \\
\hline White & 73.3 & 66.7 & 73.3 & \multirow[t]{4}{*}{0.0001} \\
\hline Brown & 20.0 & 13.3 & 20.0 & \\
\hline Black & 0.0 & 6.7 & 0.0 & \\
\hline Yellow & 6.7 & 13.3 & 6.7 & \\
\hline \multicolumn{5}{|l|}{ Marital status (\%) } \\
\hline Single & 6.7 & 6.7 & 0.0 & \\
\hline Married & 46.7 & 66.7 & 80.0 & \multirow[t]{3}{*}{0.0001} \\
\hline Divorced & 33.3 & 13.3 & 13.3 & \\
\hline Widowed & 13.3 & 13.3 & 6.7 & \\
\hline \multicolumn{5}{|l|}{ Educational level (\%) } \\
\hline Primary & 20.0 & 26.7 & 26.7 & \multirow{3}{*}{0.420} \\
\hline Secondary & 40.0 & 26.7 & 40.0 & \\
\hline Higher & 40.0 & 46.6 & 33.3 & \\
\hline \multicolumn{4}{|l|}{ Menstruation (\%) } & \multirow[t]{7}{*}{0.0001} \\
\hline Present & 20.0 & 6.7 & 26.7 & \\
\hline $\begin{array}{l}\text { Continual use of } \\
\text { contraceptives }\end{array}$ & 0.0 & 0.0 & 13.3 & \\
\hline Absent due to CA treatment & 20.0 & 13.3 & 0.0 & \\
\hline Climacteric & 0.0 & 0.0 & 13.3 & \\
\hline Menopause & 53.3 & 46.7 & 26.7 & \\
\hline Hysterectomy & 6.7 & 33.3 & 20.0 & \\
\hline \multicolumn{5}{|l|}{ Comorbidities (\%) } \\
\hline Hypertension & 40 & 33.3 & 13.3 & \multirow{6}{*}{0.0001} \\
\hline Hypercholesterolemia & 6.7 & 13.3 & 0 & \\
\hline Hypothyroidism & 0 & 13.3 & 6.7 & \\
\hline Depression & 6.7 & 20 & 0 & \\
\hline Diabetes & 6.7 & 13.3 & 0 & \\
\hline Not present & 53.3 & 26.7 & 80 & \\
\hline $\mathrm{SBP}(\mathrm{mm} \mathrm{Hg})$ & $\begin{array}{l}116.7 \pm \\
18.4\end{array}$ & $\begin{array}{l}112.7 \pm \\
15.3\end{array}$ & $\begin{array}{l}106.0 \pm \\
15.0\end{array}$ & 0.207 \\
\hline DBP (mm Hg) & $75.3 \pm 7.4$ & $70.7 \pm 7.9$ & $72.7 \pm 8.8$ & 0.297 \\
\hline RHR (bpm) & $80.7 \pm 9.6$ & $\begin{array}{l}80.7 \pm \\
10.3\end{array}$ & $79.4 \pm 5.3$ & 0.900 \\
\hline
\end{tabular}

SD: standard deviations; BMI: body mass index; $\mathrm{kg} / \mathrm{m}^{2}$ - kilograms per meter square; $\mathrm{CA}$ : cancer; SBP: systolic blood pressure; DBP: diastolic blood pressure; RHR: resting heart rate; $\mathrm{mm} \mathrm{Hg}$ - millimeters of mercury; and bpm: beat per minute.

when comparing BCG2 to CG ( $p=0.020)$. Significant changes can also be observed between the groups' HF n.u and LF n.u indexes, LF/HF and SD1/SD2 ratio $(p>0.05)$. There were no differences identified between the groups' RR intervals $(\mathrm{p}=0.288)$.

Table 2

Clinical characteristics of breast cancer groups (BCG). $\mathrm{n}=30$.

\begin{tabular}{llll}
\hline & $\begin{array}{l}\text { BCG1 } \\
(\mathrm{n}=15)\end{array}$ & $\begin{array}{l}\text { BCG2 } \\
(\mathrm{n}=15)\end{array}$ & p-Value \\
\hline $\begin{array}{l}\text { P.O. time (months) (mean } \pm \text { SD) } \\
\text { Type of surgery (\%) }\end{array}$ & $8.1 \pm 4.9$ & $67.7 \pm 35.5$ & \\
$\quad$ Mastectomy & 40.0 & 60.0 & 1.000 \\
$\quad$ Quadrantectomy & 60.0 & 40.0 & \\
Lymphadenectomy (\%) & & & 0.273 \\
$\quad$ Partial & 40.0 & 20.0 & \\
$\quad$ Total & 33.3 & 60.0 & \\
$\quad$ None & 26.7 & 20.0 & 0.0001 \\
Adjunct treatment (\%) & & & \\
$\quad$ Chemotherapy & 20.0 & 6.7 & \\
$\quad$ Radiotherapy & 13.3 & 6.7 & \\
$\quad$ Chemotherapy + radiotherapy & 46.7 & 73.3 & \\
$\quad$ None & 20.0 & 13.3 & \\
Hormonal therapy (\%) & & & \\
$\quad$ Anastrozole & 20.0 & 33.3 & \\
$\quad$ Tamoxifen & 46.7 & 46.7 & \\
None & 33.3 & 20.0 & \\
\hline
\end{tabular}

P.O. $=$ postoperative. 
Table 3

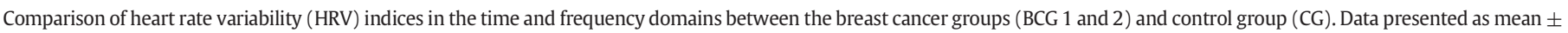
standard deviation and confidence interval 95\% followed by p-value, Eta-squared and effect size. $\mathrm{n}=45$.

\begin{tabular}{|c|c|c|c|c|c|c|}
\hline & $\begin{array}{l}\text { BCG1 } \\
(n=15)\end{array}$ & $\begin{array}{l}\text { BCG2 } \\
(n=15)\end{array}$ & $\begin{array}{l}\text { CG } \\
(n=15)\end{array}$ & p-Value & Eta-squared & Effect size \\
\hline \multicolumn{7}{|l|}{ Time domain } \\
\hline Mean RR(ms) & $\begin{array}{l}851.28 \pm 83.36 \\
{[805.1-897.4]}\end{array}$ & $\begin{array}{l}831.24 \pm 109.66 \\
{[770.5-891.9]}\end{array}$ & $\begin{array}{l}880.09 \pm 46.67 \\
{[854.2-905.9]}\end{array}$ & 0.288 & 0.209 & Large \\
\hline RMSSD (ms) & $\begin{array}{l}19.83 \pm 8.48^{\mathrm{a}} \\
{[15.1-24.5]}\end{array}$ & $\begin{array}{l}14.99 \pm 6.03^{\mathrm{a}} \\
{[11.65-18.3]}\end{array}$ & $\begin{array}{l}31.46 \pm 11.24 \\
{[25.23-37.7]}\end{array}$ & 0.0001 & 0.362 & Large \\
\hline SDNN (ms) & $\begin{array}{l}29.58 \pm 9.71^{\mathrm{a}} \\
{[24.2-34.9]}\end{array}$ & $\begin{array}{l}26.12 \pm 7.87^{\mathrm{a}} \\
{[21.8-30.5]}\end{array}$ & $\begin{array}{l}46.36 \pm 16.57 \\
{[37.2-55.5]}\end{array}$ & 0.0001 & 0.341 & Large \\
\hline \multicolumn{7}{|c|}{ Frequency domain } \\
\hline LF (n.u) & $\begin{array}{l}57.55 \pm 18.50 \\
{[47.3-67.8]}\end{array}$ & $\begin{array}{l}64.07 \pm 14.27 \\
{[56.17-71.9]}\end{array}$ & $\begin{array}{l}51.70 \pm 19.01 \\
{[41.17-62.2]}\end{array}$ & 0.162 & 0.049 & Small \\
\hline HF (n.u) & $\begin{array}{l}42.40 \pm 18.48 \\
{[32.2-52.6]}\end{array}$ & $\begin{array}{l}35.85 \pm 14.24 \\
{[27.9-43.7]}\end{array}$ & $\begin{array}{l}48.21 \pm 18.99 \\
{[37.7-58.7]}\end{array}$ & 0.162 & 0.049 & Small \\
\hline $\mathrm{LF}\left(\mathrm{ms}^{2}\right)$ & $\begin{array}{l}246.4 \pm 200.5 \\
{[135.4-357.4]}\end{array}$ & $\begin{array}{l}183.4 \pm 162.4^{\mathrm{a}} \\
{[93.5-273.3]}\end{array}$ & $\begin{array}{l}447.9 \pm 366.6 \\
{[244.8-650.9]}\end{array}$ & 0.020 & 0.167 & Large \\
\hline $\mathrm{HF}\left(\mathrm{ms}^{2}\right)$ & $\begin{array}{l}194.2 \pm 158.4^{\mathrm{a}} \\
{[106.5-281.9]}\end{array}$ & $\begin{array}{l}91.07 \pm 63.74^{\mathrm{a}} \\
{[55.8-126.4]}\end{array}$ & $\begin{array}{l}449.4 \pm 351.0 \\
{[255.0-643.8]}\end{array}$ & 0.0001 & 0.286 & Large \\
\hline $\mathrm{LF} / \mathrm{HF}\left(\mathrm{ms}^{2}\right)$ & $\begin{array}{l}1.930 \pm 1.511 \\
{[1.093-2.767]}\end{array}$ & $\begin{array}{l}2.262 \pm 1.396 \\
{[1.489-3.035]}\end{array}$ & $\begin{array}{l}1.574 \pm 1.569 \\
{[0.706-2.443]}\end{array}$ & 0.458 & 0.016 & Small \\
\hline
\end{tabular}

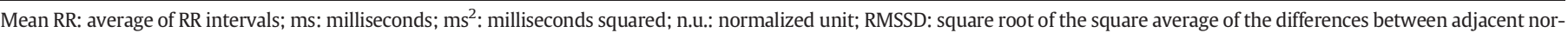

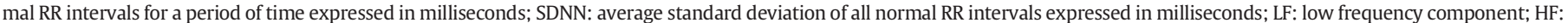
High-frequency component; and LF/HF: ratio of low frequency component/high-frequency component. Tukey Post hoc test.

a Difference with the control group.

Fig. 2 shows examples of Poincaré plot patterns in women without cancer (CG), women with a period of up to 18 months following breast cancer surgery (BCG1) and those with a period longer than 18 months (BCG2).

\section{Discussion}

The results obtained from HRV indexes suggest that breast cancer survivors, regardless of their postoperative period, present autonomic changes when compared to cancer-free women. Breast cancer survivors are characterized by a reduction of overall variability as well as sympathetic and parasympathetic activity. Comparing HRV indices between the groups of women with breast cancer shows no significant differences, except for the SD1 index which reveals a significant reduction in the group with the longer postoperative period.

In the present study, the RMSSD, SD1 and HF $\mathrm{ms}^{2}$ indexes, which reflect parasympathetic activity [6], are reduced in both groups of breast cancer survivors in relation to the group of women without the disease. This suggests that parasympathetic activity decreases in women who have had breast cancer.

Hansen et al. [4] also reported a reduction of the RMSSD index in breast cancer patients during the immediate postoperative period. Fourteen days after surgery this reduction had still not normalized. Other authors have also observed a decrease in this index in women from six months to a year after the end of their breast cancer treatment as compared to healthy women [2].

Reduced parasympathetic activity increases the risk of morbidity and mortality as well as the development of various risk factors [25,26]. In patients with metastatic or recurrent breast cancer, reduced vagal tone, verified by the HF index, correlates with a shorter survival time [27]. These results reinforce the importance of taking steps to improve cardiac autonomic modulation and minimize possible damage to the organism in breast cancer survivors, regardless of their postoperative period.

The two groups of breast cancer survivors manifested a decrease in SDNN and SD2 indexes, which represent the overall variability including both sympathetic modulation as well as parasympathetic, and LF indices in $\mathrm{ms}^{2}$ representing sympathetic activity [6]. Although the LFms ${ }^{2}$ index was reduced in the group of women whose postoperative period was no more than 18 months, they showed no significant difference when compared to women without cancer.

Like the RMSSD index [4], the SDNN index in breast cancer patients also shows a reduction in overall variability during the immediate postoperative period. This decrease in overall variability was also observed in women six months to a year after they had completed breast cancer treatment [2].

The overall variability and reduced parasympathetic activity can be observed qualitatively in the plot pattern (Fig. 2). It shows that the CG

Table 4

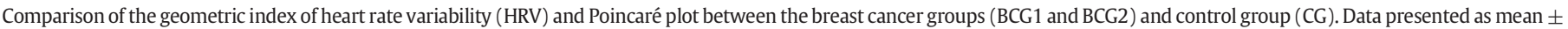
standard deviation and confidence interval 95\% followed by p-value, Eta-squared and effect size. $\mathrm{n}=45$.

\begin{tabular}{|c|c|c|c|c|c|c|}
\hline & $\begin{array}{l}\text { BCG1 } \\
(n=15)\end{array}$ & $\begin{array}{l}\text { BCG2 } \\
(n=15)\end{array}$ & $\begin{array}{l}\text { CG } \\
(n=15)\end{array}$ & p-Value & Eta-squared & Effect size \\
\hline $\mathrm{SD} 1$ (ms) & $\begin{array}{l}14.03 \pm 6.01^{\mathrm{a}} \\
{[10.70-17.37]}\end{array}$ & $\begin{array}{l}10.61 \pm 4.29^{\mathrm{ab}} \\
{[8.22-12.99]}\end{array}$ & $\begin{array}{l}22.27 \pm 7.95 \\
{[17.86-26.67]}\end{array}$ & 0.0001 & 0.659 & Large \\
\hline $\mathrm{SD} 2$ (ms) & $\begin{array}{l}39.17 \pm 13.08^{a} \\
{[31.93-46.42]}\end{array}$ & $\begin{array}{l}35.28 \pm 10.66^{\mathrm{a}} \\
{[29.38-41.18]}\end{array}$ & $\begin{array}{l}61.16 \pm 23.55 \\
{[48.12-74.20]}\end{array}$ & 0.0001 & 0.307 & Large \\
\hline $\mathrm{SD} 1 / \mathrm{SD} 2(\mathrm{~ms})$ & $\begin{array}{l}0.361 \pm 0.123 \\
{[0.293-0.429]}\end{array}$ & $\begin{array}{l}0.302 \pm 0.085 \\
{[0.255-0.349]}\end{array}$ & $\begin{array}{l}0.384 \pm 0.142 \\
{[0.305-0.463]}\end{array}$ & 0.161 & 0.052 & Small \\
\hline
\end{tabular}

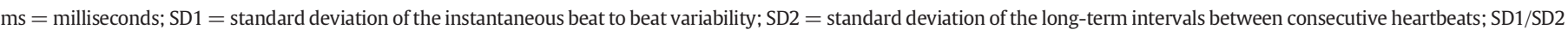
= ratio between short and long variations of RR intervals. Tukey post hoc:

a Difference with the control group.

b Difference between breast cancer groups. 

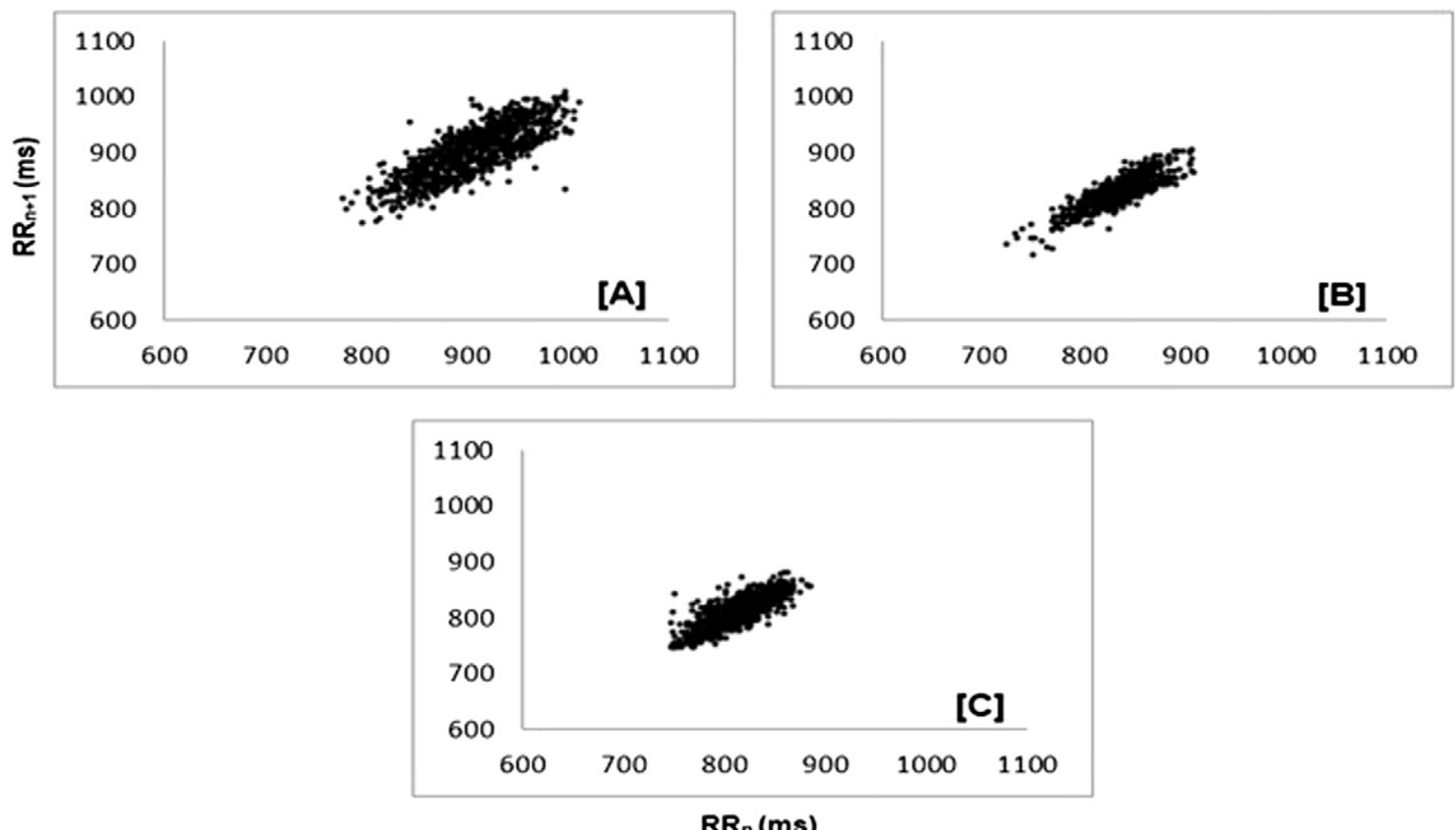

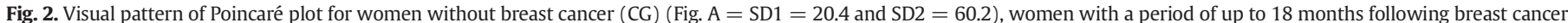
surgery (BCG1) (Fig. $\mathrm{B}=\mathrm{SD} 1$ and SD2 = $11.3=35.0$ ) and women with a postoperative period greater than 18 months $(\mathrm{BCG} 2)(\mathrm{Fig}$. $\mathrm{C}=\mathrm{SD} 1$ and SD2 $=10.4=34.3$ ).

had a greater beat-to-beat dispersion of RR intervals in both the short and long term when compared to BCG1 and BCG2.

The LF and HF indices in standard units did not differ between groups. We expected these results since these indexes in normalized units are calculated from the power spectrum of the area. This spectrum is reduced in the breast cancer groups when analyzed in $\mathrm{ms}^{2}$. Moreover, the observed reduction in the sympathetic and parasympathetic components of the ANS justifies the absence of significant differences when comparing SD1/SD2 and LF/HF between groups.

Several factors, including the type of cancer treatment, the presence of comorbidities and physical and emotional symptoms related to cancer, may alter the SNA in women and caused a decrease in HRV [2]. The tumor process may also compromise HRV due to three basic mechanisms that influence it, namely oxidative stress, exacerbated local inflammation and excessive sympathetic activity [10]. These mechanisms alter vagus nerve activity and consequently the autonomic modulation [10].

The effect size of the differences in HRV indices taken from the three groups analyzed in this study was evaluated by Eta-squared [24]. This indicated that the RMSSD, SDNN, LF $\left(\mathrm{ms}^{2}\right), \mathrm{HF}\left(\mathrm{ms}^{2}\right), \mathrm{SD} 1$ and SD2 values were significantly lower in breast cancer survivors, regardless of complicating factors such as age and BMI.

When comparing the HRV indices between the two groups of women with breast cancer, there are no significant differences except for the SD1 index. It is important to note, though, that changes in autonomic modulation were more pronounced in the group with the longer postoperative period. One thing that could explain the more significant changes is chemotherapy's cardiotoxicity, which seems to cause greater abnormalities in heart function as time passes after treatment [28].

The women with breast cancer evaluated in this study also had some characteristics that can, at least in part, be related to autonomic changes. Of the women with cancer evaluated $46.67 \%$ of BCG1 and $73.33 \%$ of BCG2 had some type of comorbidity. Furthermore, $66.7 \%$ of BCG1 and $80 \%$ of BCG2 underwent complementary treatment with chemotherapy and $60 \%$ of BCG 1 and $80 \%$ of BCG 2 received radiotherapy. Radiation therapy is an adjunctive technique to surgery, which minimizes the possibility of the cancer's recurrence and increases patient survival.
However, adjacent tissues, such as the heart in the case of breast cancer, can be exposed to radiation since it is near the target area [29]. This exposure, along with chemotherapeutic agents, can lead to early and late toxicity [30,31]. According to Ording et al. [32], comorbidities among breast cancer survivors treated with chemotherapy and radiation therapy were more likely to be fatal than among those who just received hormone therapy.

This study has some limitations, such as the presence of comorbidities in the population being studied and the possibility of reverse causality, because it is a cross-sectional study. It is important to note the aspects which set this study apart from others, for instance this study analyzes HRV indexes using different domains and at different times following breast cancer surgery, plus it was adjusted for complicating factors such as age and weight.

It is also important to note that an individual's characteristics (age, gender, ethnicity, hormonal changes, circadian rhythm, presence of acute and chronic diseases, psychiatric disorders and lifestyle such as physical fitness, increased body weight, active or passive smoking and alcohol abuse) or conditions in their living environment (climatic factors, noise exposure, working the night shift for many years, use of medications) can influence HRV [33]. During this study, however, we sought to control these factors.

In summary, the results of this study suggest that breast cancer survivors, regardless of their postoperative period, show decreased overall variability and both sympathetic and parasympathetic activity when compared to cancer-free women. This study also indicates that the group of women with the longer postoperative period manifests more pronounced autonomic modulation changes. These results reinforce the need for prevention and treatment among breast cancer survivors and emphasize the importance of using multidisciplinary approaches to enhance the physical, emotional and social wellbeing of this segment of the population.

\section{Conflict of interest}

The authors report no relationships that could be construed as a conflict of interest. 


\section{References}

[1] International Agency for Research on Cancer, Latest world cancer statistics global cancer burden rises to 14.1 million new cases in 2012: marked increase in breast cancers must be addressed, http://www.iarc.fr/en/media-centre/pr/2013/pdfs/ pr223_E.pdf2013.

[2] E. Caro-Morán, C. Fernández-Lao, N. Galiano-Castillo, I. Cantarero-Villanueva, M. Arroyo-Morales, L. Díaz-Rodríguez, Heart rate variability in breast cancer survivors after the first year of treatments: a case-controlled study, Biol. Res. Nurs. (2015)http://dx.doi.org/10.1177/1099800414568100.

[3] A.C. Cameron, R.M. Touyz, N.N. Lang, Vascular complications of cancer chemotherapy, Can. J. Cardiol. (2015)http://dx.doi.org/10.1016/j.cjca.2015.12.023.

[4] M.V. Hansen, J. Rosenberg, I. Gögenur, Lack of circadian variation and reduction of heart rate variability in women with breast cancer undergoing lumpectomy: a descriptive study, Breast Cancer Res. Treat. 140 (2) (2013) 317-322.

[5] M.D. Couck, R. Maréchal, S. Moorthamers, J.L. Laethem, Y. Gidron, Vagal nerve activity predicts overall survival in metastatic pancreatic cancer, mediated by inflammation, Cancer Epidemiol. 40 (2016) 47-51.

[6] L.C.M. Vanderlei, C.M. Pastre, R.A. Hoshi, T.D. Carvalho, M.F. Godoy, Basic notions of heart rate variability and its clinical applicability, Rev. Bras. Cir. Cardiovasc. 24 (2) (2009) 205-217.

[7] L. Compostella, N. Russo, C. Compostella, T. Setzu, A. D'Onofrio, G. Isabella, et al., Impact of type of intervention for aortic valve replacement on heart rate variability, Int. J. Cardiol. 197 (2015) 11-15.

[8] L.D. Novais, D.I. Sakabe, A.C.M. Takahashi, H. Gongora, C. Taciro, L.E.B. Martins, et al. Assessment of heart rate variability at rest in sedentary healthy men and of hypertensive and coronary artery disease in physical training, Rev. Bras. Fisioter. 8 (3) (2004) 207-213.

[9] G. Litscher, W. He, S.H. Yi, L. Wang, Heart rate variability and complementary medicine, Evid. Based Complement. Alternat. Med. 2014 (2014) 395485.

[10] M. De Couck, Y. Gidron, Norms of vagal nerve activity, indexed by heart rate variability, in cancer patients, Cancer Epidemiol. 37 (5) (2013) 737-741.

[11] L. Cramer, B. Hildebrandt, T. Kung, K. Wichmann, J. Springer, W. Doehner, A. Sandek M. Valentova, T. Stojakovic, H. Scharnagl, H. Riess, S.D. Anker, S. Von Haehling, Cardiovascular function and predictors of exercise capacity in patients with colorectal cancer, J. Am. Coll. Cardiol. 64 (13) (2014) 1310-1319.

[12] J. Kalseth, T. Halvorsen, B. Kalseth, K. SarheimAnthun, M. Peltola, K. Kautiainen, et al., Cross-country comparisons of health-care costs: the case of cancer treatment in the Nordic countries, Health Policy 115 (2-3) (2014) 172-179.

[13] E.M.C. Ramos, L.C.M. Vanderlei, D. Ramos, L.M. Teixeira, F. Pitta, M. Veloso, Influence of pursed-lip breathing on heart rate variability and cardiorespiratory parameters in subjects with chronic obstructive pulmonary disease (COPD), Rev. Bras. Fisioter. 13 (4) (2009) 288-293.

[14] S. Torrealday, L. Pal, Premature menopause, Endocrinol. Metab. Clin. N. Am. 44 (3) (2015) 543-557.

[15] F.A.C. Rezende, L.E.F.P.L. Rosado, S.C.C. Franceschinni, G.P. Rosado, R.C.L. Ribeiro, The body mass index applicability in the body fat assessment, Rev. Bras. Med. Esporte 16 (2) (2010) 90-94.

[16] J.P. Andrade (Ed.), VI Diretrizes Brasileiras de Hipertensão, Arq Bras Cardiol, Vol. 95(1 supl.1), 2010, pp. 1-51.
[17] F.X. Gamelin, S. Berthoin, L. Bosquet, Validity of the polar S810 heart rate monitor to measure R-R intervals at rest, Med. Sci. Sports Exerc. 38 (5) (2006) 887-893.

[18] M. Kingsley, M.J. Lewis, R.E. Marson, Comparison of polar S810s and an ambulatory ECG system for RR interval measurement during progressive exercise, Int. J. Sports Med. 26 (2005) 39-44.

[19] M.F. Godoy, I.T. Takakura, P.R. Correa, Relevance of the analysis of the nonlinear dynamic behavior (chaos theory) as a prognostic factor of morbidity and mortality in patients undergoing coronary artery bypass surgery, Arq. Ciênc. Saúde 12 (4) (2005) 167-171.

[20] M.P. Tarvainen, J.P. Niskanen, J.A. Lipponen, P.O. Ranta-aho, P.A. Karjalainen, Kubios HRV - heart rate variability analysis software, Comput. Methods Prog. Biomed. 113 (1) (2014) 210-220

[21] V.R.F.S. Marães, L.C.A. Teixeira, A.M. Catai, L.A. Milan, F.A.R. Rojas, L. Oliveira, et al., Determination and validation of the anaerobic threshold by methods of the analyses of the heart rate and its variability, Rev. Soc. Cardiol. Estado São Paulo 13 (4) (2003) 1-13.

[22] A.F. Brunetto, B.T. Roseguini, B.M. Silva, D.M. Hirai, D.P. Guedes, Cardiac autonomic responses to head-up tilt in obese adolescents, Rev. Assoc. Med. Bras. 51 (5) (2005) 256-260.

[23] M.P. Tulppo, T.H. Mäkikallio, T. Seppänen, R.T. Laukkanen, H.V. Huikuri, Vagal modulation of heart rate during exercise: effects of age and physical fitness, Am. J. Phys. 274 (2Pt 2) (1998) H424-H429.

[24] J.M. Maher, J.C. Markey, D. Ebert-May, The other half of the story: effect size analysis in quantitative research, CBE Life Sci. Educ. 12 (3) (2013) 345-351.

[25] L.C.M. Vanderlei, C.M. Pastre, I.F. Freitas Júnior, M.F. Godoy, Geometric indexes of heart rate variability in obese and eutrophic children, Arq. Bras. Cardiol. 95 (1) (2010) 35-40.

[26] J.F. Thayer, R.D. Lane, The role of vagal function in the risk for cardiovascular disease and mortality, Biol. Psychol. 74 (2) (2007) 224-242.

[27] J. Giese-Davis, F.H. Wilhelm, R. Tamagawa, O. Palesh, E. Neri, C.B. Taylor, et al., Higher vagal activity as related to survival in patients with advanced breast cancer: an analysis of autonomic dysregulation, Psychosom. Med. 77 (4) (2015) 346-355.

[28] J.R. Carver, C.L. Shapiro, A. Ng, L. Jacobs, C. Schwartz, K.S. Virgo, et al., American Society of Clinical Oncology clinical evidence review on the ongoing care of adult cancer survivors: cardiac and pulmonary late effects, J. Clin. Oncol. 25 (25) (2007) 3991-4008.

[29] C.W. Taylor, A.M. Kirby, Cardiac side-effects from breast cancer radiotherapy, Clin. Oncol. (R. Coll. Radiol.) (2015)http://dx.doi.org/10.1016/j.clon.2015.06.007.

[30] G. Lee, T. Rosewall, A. Fyles, N. Harnett, R.E. Dinniwell, Anatomic features of interest in women at risk of cardiac exposure from whole breast radiotherapy, Radiother. Oncol. 115 (3) (2015) 355-360.

[31] A.A. Kirkham, M.K. Davis, Exercise prevention of cardiovascular disease in breast cancer survivors, J. Oncol. 2015 (2015) 917606.

[32] A.G. Ording, P. Boffetta, J.P. Garne, P.M. Nyström, D. Cronin-Fenton, T. Frøslev, R. Silliman, H.T. Sørensen, T.L. Lash, Relative mortality rates from incident chronic diseases among breast cancer survivors - a 14 year follow-up of five-year survivors diagnosed in Denmark between 1994 and 2007, Eur. J. Cancer 51 (6) (2015) 767-775.

[33] S. Sammito, I. Böckelmann, Factors influencing heart rate variability, Int. Cardiovasc. Forum J. 6 (2016) 18-22 